\title{
Refletindo sobre a inovação farmacêutica e seus impactos no acesso aos medicamentos
}

\author{
Reflecting on pharmaceutical innovations \\ and their impact on access to medications
}

\author{
José Augusto Cabral de Barros \\ Professor visitante da Universidade Federal de Juiz de Fora. \\ josebarros@uol.com.br
}

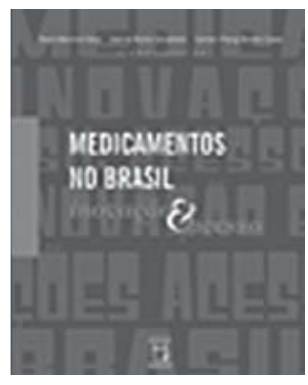

BUSS, Paulo Marchiori; CARVALHEIRO, José da Rocha; ROMERO CASAS, Carmem Phang (Org). Medicamentos no Brasil: inovação e acesso. Rio de Janeiro: Editora Fiocruz. 2008. 440p.

\begin{abstract}
A despeito da multiplicação mais recente de textos, sob a forma de artigos e/ou livros, frutos de trabalhos de revisão ou de estudos originais, voltados para o que se designa estudos de utilização de medicamentos, o enfoque abrangente e os temas específicos abordados em Medicamentos no Brasil: inovação e acesso vêm preencher uma lacuna, oferecendo subsídios para ampliar a reflexão sobre os problemas que envolvem a pesquisa e o consumo de medicamentos, além de atender aos interessados em temas de farmacoepidemiologia de maneira geral.

O fenômeno designado como doença é complexo. Além de componentes de natureza subjetiva, implica uma série de determinantes de caráter socioeconômico e cultural. Normalmente demanda uma alternativa terapêutica que, com grande frequência, se orienta para a ida a um serviço de saúde ou a uma farmácia, resultando na opção prioritária por um produto alopático.
\end{abstract}

Os medicamentos, sobretudo a partir da quimiossíntese industrial ocorrida no século $\mathrm{XX}$, têm assumido a condição de bem de consumo (mercadoria) dotado de um princípio ativo (entidade molecular com potencial efeito terapêutico, que pode ser acompanhado de efeitos adversos). Muitos estudos têm ressaltado a sinergia existente entre a lógica de mercado e a visão reducionista do fenômeno saúde/doença (modelo biomédico), que contribui para intensificar o fenômeno designado como medicalização, com as implicações éticas e sócio-sanitárias decorrentes. Criou-se uma verdadeira 'cultura da pílula', pois interessa à indústria farmacêutica ter consumidores constantes e acríticos, dependentes desses insumos, os quais passam a ser percebidos e utilizados como a principal, se não a única, fonte de bem-estar e saúde (Barros, 2002, 2008a). Os médicos, por sua vez, alvo de estratégias publicitárias intensivas e cada vez mais amplas e sofisticadas, são induzidos a prescrever medicamentos com base em informações que lhes são repassadas pelos produtores, com o viés mercadológico a elas inerente. Vale lembrar que os gastos com atividades promocionais são maiores do que os de pesquisa e desenvolvimento de novos fármacos (Barros, 2004). 
No que se refere à intromissão dos interesses de mercado na pesquisa, os ensaios clínicos nos Estados Unidos, antes centrados em organismos estatais ou em instituições acadêmicas são agora, em grande parte, realizados por empresas privadas, criadas com esse propósito sob contrato do setor farmacêutico (Angell, 2007; Barros, 2008b). É preocupante verificar que resultados de pesquisas podem ser manipulados. Artigos têm sido elaborados por médicos especializados nessa tarefa - os chamados ghost-writers - e vêm sendo publicados sob nome de pesquisadores ou docentes renomados (Elliot, 2010).

O uso excessivo e inadequado da medicação termina por provocar desperdício de recursos e resulta em dano significativo ao paciente, por conta dos resultados insatisfatórios e da multiplicação dos efeitos adversos. Ressalte-se que ao mesmo tempo em que ocorre um consumo de medicamentos supérfluos ou injustificados (como no caso dos polivitaminícos) há, sobretudo em países subdesenvolvidos, carência de medicamentos essenciais.

O livro em foco se constitui em mais um produto do projeto Inovação em Saúde, desenvolvido pela Fiocruz, cujo primeiro volume foi Vacinas, soros e imunizações no Brasil (2005). Esse segundo tomo é voltado para as especificidades do setor produtivo de fármacos e medicamentos, no âmbito da política setorial de ciência e tecnologia a eles relacionada.

O capítulo inicial do livro, "Do complexo médico-industrial ao complexo industrial da saúde", apresenta o referencial teórico necessário para melhor compreensão da dinâmica econômica dos setores de bens e serviços relacionados à saúde, tendo como eixo a indústria farmacêutica. Discorre de forma bastante apropriada sobre o complexo médico-industrial e o complexo industrial da saúde.

Ainda que se explicite a opção por autores brasileiros como referencial para o enfoque desse capítulo introdutório, parece-nos que o impacto e consistência das contribuições de Vicente Navarro e Ivan Illich deveriam ter sido consideradas em virtude da reflexão feita por eles - em grande medida pioneira - sobre as consequências do processo de sofisticação tecnológica e industrialização no âmbito da medicina e do fenômeno designado como medicalização (Illich, 1975; Navarro, 1975; Barros, 2008a).

O livro oferece extensa discussão a respeito dos problemas e perspectivas da produção e da inovação farmacêuticas, tendo sido elaborado um quadro bastante amplo no qual são explorados os setores público e privado como agentes desses processos no país. Essa discussão é feita particularmente nos capítulos 5 a 14, este último dedicado ao potencial dos fitoterápicos.

Reunindo recursos humanos qualificados que atuam formando uma rede, cabe realçar o empenho da Fiocruz ao institucionalizar (cf. capítulo 6), em 2002, o Programa de Desenvolvimento Tecnológico em Insumos para a Saúde e, a posteriori, como desdobramento do mencionado programa, as Redes de Plataformas Tecnológicas, uma das quais voltada para fármacos, a Rede de Medicamentos e Bioinseticidas. Uma iniciativa recente e com potencial de grande impacto, e que segue igualmente o modelo de trabalho cooperativo, agregando ampla gama de instituições públicas de pesquisa e ensino foi a criação, em 2008, do Instituto Nacional de Ciência, Tecnologia e Inovação Farmacêutica (INCT-IF), do qual fazem parte, além das instituições acadêmicas, órgãos como CNPq, Capes, Petrobras e BNDES. Integrando os 101 institutos nacionais de ciência e tecnologia, criados em 16 unidades da federação, o INCT-IF está sediado na Universidade Federal de Pernambuco (UFPE). ${ }^{1}$ São cerca de quatrocentos pesquisadores de todo o país, que atuam em diferentes 
vertentes das ciências farmacêuticas, organizados em oitos redes temáticas relacionadas à cadeia da inovação farmacêutica. ${ }^{2}$

Em relação à propriedade intelectual há autores que divergem do ponto de vista apontado no texto, ao menos em relação a algumas das ideias explicitadas no capítulo 5, "Desenvolvimento tecnológico em medicamentos na indústria farmacêutica brasileira". É fato conhecido que as novas regras que passaram a dominar o intercâmbio comercial entre países sofreram alterações significativas a partir da criação da Organização Mundial de Comércio (OMC) em janeiro de 1995. Um dos aspectos de maior importância para os países subdesenvolvidos certamente reside no pressuposto proclamado quando da criação da OMC, segundo o qual as regras introduzidas para os direitos de propriedade intelectual provocariam o aumento da transferência e da difusão da tecnologia, incremento do investimento direto estrangeiro e reforço da pesquisa e do desenvolvimento locais; impactos que não vêm sendo observados na prática.

O acordo firmado por 105 países, inclusive o Brasil, designado Trade Related Intellectual Property Rights Agreement (Trips) [Acordo sobre aspectos do direito de propriedade intelectual relacionados ao comércio], além de representar uma transferência de poder dos países para corporações transnacionais, pode ser considerado de fato, de acordo com Balasubramaniam (1998), "o acordo com maior grau de não transparência, desprovido de responsabilidade pública, antipovo e pró transnacionais da história das negociações e acordos internacionais" (citado por Barros, 2004, p.59). Conforme o autor "o acordo Trips, em particular, negará a bilhões de pobres (homens, mulheres e crianças) de todo o mundo, o acesso até mesmo a um número limitado de medicamentos essenciais para o tratamento de doenças comuns" (Balasubramaniam, 1998, citado por Barros, 2004, p.59). As reflexões de Correa sobre o impacto desses acordos no âmbito da saúde pública, sobre a introdução dos genéricos e o regime a ser observado com respeito às patentes ${ }^{3}$ merecem nossa atenção por tornar claros os impactos das novas regras estabelecidas (Correa, 1997, 2001, 2002).

A trajetória percorrida e os conflitos surgidos na tentativa de preservar os interesses da saúde pública frente aos dos produtores de medicamentos, nos fóruns da Organização Mundial de Saúde (OMS) e da OMC, são apresentados de forma exaustiva no capítulo 20, "Pesquisa, desenvolvimento e inovação em medicamentos".

Parece-nos oportuno voltar a comentar o capítulo 5, que se beneficiaria de considerações sobre a ausência de proteção patentária no Brasil e suas implicações. A proteção patentária existente não estimulou, nos seus 55 anos de vigência, a criação de uma base tecnológica no país. Esse aspecto é retomado no capítulo 18, que também destaca que as múltiplas iniciativas de feição neoliberal implementadas a partir do início dos anos 1990 pouco contribuíram para a formação de uma cultura tecnológica inovadora. Caberia questionar se isso foi decorrente da falta de capital e/ou vontade política da época ou do pouco apoio logístico e financeiro por parte do governo. Essa situação talvez se altere com o Programa de Apoio ao Desenvolvimento da Cadeia Produtiva Farmacêutica, lançado em 2004 com auxílio do BNDES, Finep e outras agências de financiamento, que tem permitido a necessária interação da academia com a indústria. Ademais cabe realçar o papel positivo das leis de inovação surgidas em 2004. Nesse debate deve-se lembrar que continua havendo clara concentração do registro de patentes em poucos países - os desenvolvidos. Verifica-se que 
os fármacos inovadores surgidos entre 1955 e 1989, em aproximadamente 92\% dos casos, concentravam-se em apenas 16 dos 95 países que, à época das mencionadas inovações, respeitavam patentes (Barros, 2004).

No capítulo 20, "Pesquisa, desenvolvimento e inovação em medicamentos", é realizada interessante e oportuna reflexão sobre as implicações e desdobramentos dos acordos Trips, sendo traçada uma trajetória das tentativas de fazer prevalecerem os interesses da saúde pública nos fóruns da OMC e da OMS.

Em geral é difícil um livro discutir tema tão complexo, no qual estão em jogo tantas variáveis e interesses, com a amplitude e profundidade necessárias. De todo modo o texto oferece uma contribuição significativa ao debate, explicitando caminhos já trilhados e apresentando perspectivas no que diz respeito às inovações e ao acesso aos medicamentos.

Tal como é apontado no capítulo 20, a discussão dos problemas envolvidos nas questões abordadas pelo livro implica questionamentos fundamentais. Esses devem ser feitos dentro de uma ampla e imprescindível revisão dos conflitos e das possibilidades de avanços, no contexto dos interesses dos países em desenvolvimento em relação aos acordos Trips. Deveriam ser discutidas, por exemplo, estratégias para superação das doenças tidas como negligenciadas. Saúde ou comércio? Para onde tendem as políticas de Estado?

\section{NOTAS}

${ }^{1}$ Já em 2008 é lançado o Programa de Pós-graduação em Inovação Terapêutica da UFPE. Os cursos de mestrado e doutorado têm como área de concentração 'insumos, fármacos e medicamentos: do fundamental ao aplicado'.

${ }^{2}$ As oito redes temáticas de pesquisa são: assistência farmacêutica e vigilância sanitária, avaliação da atividade biológica, biotecnologia farmacêutica, nanotecnologia farmacêutica, produtos naturais bioativos, síntese de fármacos, tecnologia farmacêutica e controle de qualidade e toxicologia (para mais informações em www.ufpe.br/inct_if/_proposta_criacao/index.html).

${ }^{3}$ Sobre a tentativa de prorrogar sua vigência, ver comentários e denúncias feitas por Angell, 2007.

\section{REFERÊNCIAS}

ANGELL, Marcia.

A verdade sobre os laboratórios farmacêuticos: como somos enganados e o que podemos fazer a respeito. Rio de Janeiro: Record. 2007.

BALASUBRAMANIAM, K.

Heads-TNCs win: tails-south loses or the GATT/

WTO/TRIPs Agreement. Penang: Consumers Internacional. 1998.

BARROS, José Augusto Cabral de.

Nuevas tendencias de la medicalización. Ciência e Saúde Coletiva, Rio de Janeiro, v.13, supl., p.579-587. 2008a.

BARROS, José Augusto Cabral de.

Os fármacos na atualidade: antigos e novos desafios. Brasília: Editora da Anvisa. 2008b.

BARROS, José Augusto Cabral de.

Políticas farmacêuticas: a serviço dos interesses da saúde? Brasília: Unesco; Editora da Anvisa. 2004.

BARROS, José Augusto Cabral de. Pensando o processo saúde e doença: a quem serve o modelo biomédico? Saúde e Sociedade, São Paulo, v.11, n.1, p.7-84. 2002.

CORREA, Carlos M.

Implications of the Doha Declaration on the TRIPs Agreement and public health. Geneva: World Health Organization. Disponível em: http://apps.who.int/medicinedocs/pdf/s2301e/ s2301e.pdf . Acesso em 5 set. 2011. 2002.

CORREA, Carlos M.

Tendencias en el patentamiento farmacéutico: estudio de casos. Buenos Aires: Corregidor. 2001. 
CORREA, Carlos M.

Los acuerdos de la Ronda Uruguay y los medicamentos. In: Lobo, F.; Velaquez, G. (Org.).

Los medicamentos ante las nuevas realidades económicas. Madrid: Civitas. p.53-84. 1997.

ELLIOT, Carl.

White coat, black hat: adventures on the dark side of medicine. Boston: Beacon Press. 2010.
ILLICH, Ivan.

A expropriação da saúde: nêmesis da medicina. Rio de Janeiro: Nova Fronteira. 1975

NAVARRO, Vicente.

La industrialización del fetichismo o el fetichismo de la industrialización: a propósito de némesis médica. Barcelona: Anagrama. 1975. 